\title{
Teaching clinical anatomy of the female pelvic floor to undergraduate students: a critical review of neuralgic points ${ }^{*}$
}

\author{
Beat M. Riederer ${ }^{1}$, Jean-Pierre Spinosa ${ }^{1,2}$ \\ ${ }^{1}$ Department of Cellular Biology and Morphology, University of Lausanne, Lausanne, Switzerland \\ ${ }^{2}$ Private Practice, Switzerland
}

\begin{abstract}
Pelvic floor anatomy is complex and its three-dimensional organization is often difficult to understand for both undergraduate and postgraduate students. Here, we focused on several critical points that need to be considered when teaching the perineum. We have to deal with a mixed population of students and with a variety of interest. Yet, a perfect knowledge of the pelvic floor is the basis for any gynecologist and for any surgical intervention. Our objectives are several-fold; i) to establish the objectives and the best way of teaching, ii) to identify and localize areas in the female pelvic floor that are susceptible to generate problems in understanding the three-dimensional organization, iii) to create novel approaches by respecting the anatomical surroundings, and iv) prospectively, to identify elements that may create problems during surgery i.e. to have a closer look at nerve trajectories and on compression sites that may cause neuralgia or postoperative pain. A feedback from students concludes that they have difficulties to assimilate this much information, especially the different imaging techniques. Eventually, this will lead to a severe selection of what has to be taught and included in lectures or practicals. Another consequence is that more time to study prosected pelves needs to be given.
\end{abstract}

Key words: levator ani nerve; pelvis; neuralgia; pudendal nerve branches; sacrospinous ligament; teaching; variations

Anatomy 2011;5:1-6, (c) 2011 TSACA

\section{Introduction}

The most important question to ask, when teaching medical students is: what are the most important topics to deal with when presenting the pelvic floor anatomy to undergraduate students or to physicians. From a gynecologist point-of-view, everything is important, but having constraints in lecture and dissection time, it is essential to focus on some topics and to insist on the importance for the future trade of a physician, without neglecting a general anatomical view of the pelvic floor of men and women. Since the Bologna System was introduced in Europe, students have to do a master degree, and we had several students that showed interest in our work, how to improve teaching of the pelvic floor with different techniques.

There exist many excellent standard anatomical books. ${ }^{[1-3]}$ In addition, a variety of anatomical and clinically related papers and reviews have been published; with reference to innervation and muscle function, ${ }^{[4-8]}$ or on pelvic fasciae, ${ }^{[9,10]}$ supporting the view that anatomical knowledge is important. ${ }^{[1]}$ Of particular interest are aspects such as i) the urethral sphincter anatomy ${ }^{[12,13]}$ its function, ${ }^{[14,15]}$ urinary incontinence ${ }^{[12]}$ and corrective surgery and postoperative complications $;{ }^{[16,17]}$ ii) the anal sphincter with fecal incontinence ${ }^{[18,19]}$ Also, other explanations for pelvic pain need to be considered. ${ }^{[20-26]}$

*Presented at the 17th Congress of IFAA in Cape Town, South Africa, at the education session, August 17, 2009. 
At the University of Lausanne, Switzerland, pelvis and pelvic floor anatomy of men and women is taught in the second year of medical studies; this includes also students from dentistry and psychiatric curricula. Teaching is done in form of four periods of ex cathedra lectures, three hours of pelvic dissection to realize the complexity of the region, and two hours of self-directed learning on prosected and plastinated specimens of the pelvic floor to understand the three-dimensional organization.

Teaching the pelvic floor anatomy is not easy, given also the limited time at disposition and considering the level of knowledge of the students. Here, we review how to approach this difficult region, we consider both anatomical, gynecological and surgical aspects and weight the importance and objectives what needs to be taught to undergraduate students.

\section{Some Methodological Aspects}

Cadavers, are obtained through the donation program of our Department and were perfused through the femoral artery with a mixture of $0.9 \mathrm{~L}$ of formaldehyde (38\%), $0.5 \mathrm{~L}$ of phenol (85\%), $1.0 \mathrm{~L}$ of glycerol (85\%), $4.0 \mathrm{~L}$ of ethanol $(94 \%)$ and $10.6 \mathrm{~L}$ of water. The cadavers were wrapped in plastic bags to prevent desiccation, stored at $8^{\circ} \mathrm{C}$ until dissected by second year medical students as part of their training. Several well dissected parts and slices were used for a permanent preservation by plastination. Dissection of fixed cadavers is an essential step in the acquisition of anatomical knowledge.

Plastination of specimens was done by the standard S10 method described by von Hagens. ${ }^{[27]}$ In short: at room temperature, specimens are dehydrated by incubations at increasing concentrations of alcohol, are then placed in acetone at $4^{\circ} \mathrm{C}$, finally at $-20^{\circ} \mathrm{C}$. Impregnation with Silicon $\mathrm{S} 10$ is performed at $-20^{\circ} \mathrm{C}$ by applying a vacuum and reducing the air pressure gradually over a period of 7 days. Curing is done with S6 accelerator. Plastinated specimens have considerable advantages, they allow a three-dimensional view of specific regions, easy to handle and are the preferred tool in self-directed learning.

\section{Critical Points in Teaching}

Within 4 periods of lecture time, all aspects of the pelvic anatomy of men and women have to be presented, with examples drawn from various anatomy books and examples from our large collection of specimens to illustrate various aspects and complexity of this region. An important question is, if anatomical variations need to be taught already at undergraduate level. Students complain that there is too much matter presented, while in clinical years, professors complain that the students know too little. Therefore, we present here an example that considers several critical points in innervation and that can be included in 2nd year medical teaching to document the relationship between anatomy, innervation variation, nerve compression and pelvic pain.

\section{Levator ani muscle and its direct innervation by the sacral plexus}

The levator ani muscle (LAM) is comprised of the iliococcygeus, the pubococcygeus and the puborectalis muscles. Together with the coccygeus muscle and the perineal membrane $(\mathrm{PeM})$ they constitute the pelvic floor diaphragm. The PeM was formerly called urogenital diaphragm and is composed of the deep and superficial transverse perineal muscles and their fasciae, and forming anteriorly the transverse perineal ligament. For one, the LAM is innervated by its own nerve, the levator ani nerve (LAN) coming from sacral plexus S3 and/or S4, as seen in Figures $\mathbf{1}$ and 2a, innervating the visceral side of the LAM. Secondly, branches from the pudendal nerve (S2-S4) reach the LAM on the inferior side, either via the inferior rectal nerve or some perineal branches. ${ }^{[8]}$

\section{Pudendal nerve branching and variations}

Two variations are prevalent in the pudendal nerve $(\mathrm{PuN})$ and its branches: in $60 \%$ the inferior rectal nerve (IRN) originates from the pudendal nerve in the proximal part of the pudendal canal, ${ }^{[8,28]}$ termed "classical IRN". The second type was termed "variant IRN", found in $40 \%$ of cases, and characterized by an IRN, independent from the pudendal nerve, originating directly from the $\mathrm{S} 3$ and $\mathrm{S} 4$ roots of the sacral plexus. In the later case, the IRN is not passing through the pudendal canal and runs directly through the ischio-anal fossa to the external anal sphincter (EAS) muscle and to the LAM. Actually, Shafik et al. described this variant in $30 \%$ of cases and termed this nerve branch "accessory rectal nerve" ${ }^{\text {"[29] }}$ (Figure 2b). When the IRN is running directly and as separate branch into the ischio-anal fossa towards the posterior part of the (EAS), there may be less constriction on the nerve. Often, the $\mathrm{PuN}$ is passing into the pudendal canal already separated in several branches destined for various organs of the perineum. Actually, the PuN may be separated already into several perineal branches when passing between the sacrotuberous and sacrospinous ligaments STL and SSL and entering the pudendal canal. This may become important when it comes to localizing pain due to nerve entrapment. Pudendal neuralgia may be a result of nerve compression in the pudendal canal, and may par- 
tially explain pelvic pain. ${ }^{[20,21]}$ A second possibility is, that a compression of $\mathrm{PuN}$ and IRN may occur when passing between the two ligaments, SSL and STL, and as such form a ligament clamp (Figures 1 and 2c). This ligament clamp is in $70 \%$ cause for pelvic pain, while in $20 \%$ of cases the origin for pelvic pain comes from a compression by the pudendal canal itself. ${ }^{[22]}$ We have recently shown, that it is possible to narrow down the site of nerve entrapment as a source of pain, by measuring and comparing motor latencies of LAM, and anterior and posterior parts of the EAS. ${ }^{[2]}$ For pain relieve, either the "sacro-spinotuberous" ligament grip or the pudendal canal are opened..$^{[2-22,30]}$

\section{Nerve trajectories and their relation to the sacrospinous ligament}

In uterine prolapse, a vaginal fixation on the SSL by the vaginal route was introduced by Richter and Albrich. ${ }^{[3]} \mathrm{It}$ is therefore of importance to look at the exact trajectories of the different nerves in relation to this ligament. The nerve passage and variations near the ischial spine have been explored by several groups. ${ }^{[7,8,32]}$ The levator ani nerve, the IRN (variant) and the PuN are passing medial to the ischial spine at a mean distance of $25 \mathrm{~mm}$, $19 \mathrm{~mm}$, and $6 \mathrm{~mm}$, respectively. For example the dis- tance from the LAN to the ischial spine varies between 3 $\mathrm{mm}$ to $25 \mathrm{~mm}$. All three nerves are in close contact with the SSL or may even perforate this ligament. The fact that after hysterectomy or vaginal prolapse this ligament serves as a fixation of the vagina, makes it important to put a fixation more medially and closer to the sacrum rather than towards the ischial spine, in order to avoid any nerve entrapment. Indeed, there are several reports of ipsilateral buttock pain after SSL fixation, that most likely can be explained as postoperative neuropathy, as a consequence of nerve entrapment. ${ }^{[3,34]}$

\section{The Alcock's or pudendal canal and nerve trajectories}

In $1839 \mathrm{~B}$. Alcock described the trajectory of the pudendal artery in the Cyclopedia of Anatomy and Physiology in a chapter entitled "iliac arteries": ${ }^{[3]}$ several points transpire from the early description of this membranous canal: i) the canal is formed by the fascia of the internal obturator muscle, ii) there are anatomical variations, and iii) the canal follows a convex trajectory.

The terminal branch of the PuN, the dorsal nerve of the clitoris (DNC), may be already detached near the ischial spine (in 5 out of 7 cases) ${ }^{[29]}$ and then runs straight towards the pubic angle as a separate nerve, whereas per-
Figure 1. Schematic view of pelvic floor (gynecological view) to highlight some crucial points of pelvic floor innervation by the levator ani and pudendal nerves respectively, since it applies to variations found in the male and female pelvic floor. (a) Passage of the levator ani nerve (LAN) to the superior surface (visceral side) of the levator ani muscle (LAM). (b) Passage of the pudendal nerve (PuN) between piriformis and coccygeus muscles, and posterior to the sacrospinous ligament (SSL); at this place the PuN may be already separated into inferior rectal nerve (IRN), as well as perineal nerves (PeN); and both sacrospinous and sacrotuberous ligaments (STL) may compress the passing nerv(es). (c) Entry of PuN into pudendal canal, while the IRN enters the ischio-anal fossa and directs towards the external anal sphincter (EAS) muscle. (d) PeN branches leave the pudendal canal for the innervation of different elements in the anterior triangle as well as anterior part of EAS. These four points are illustrated and further commented in subsequent figures and in text. BSM: bulbospongiosus muscle; DNC: dorsal nerve of the clitoris; ICM: ischicavernosus muscle; IOM: internal obturator muscle; PeB: perineal body; PeM: perineal membrane.

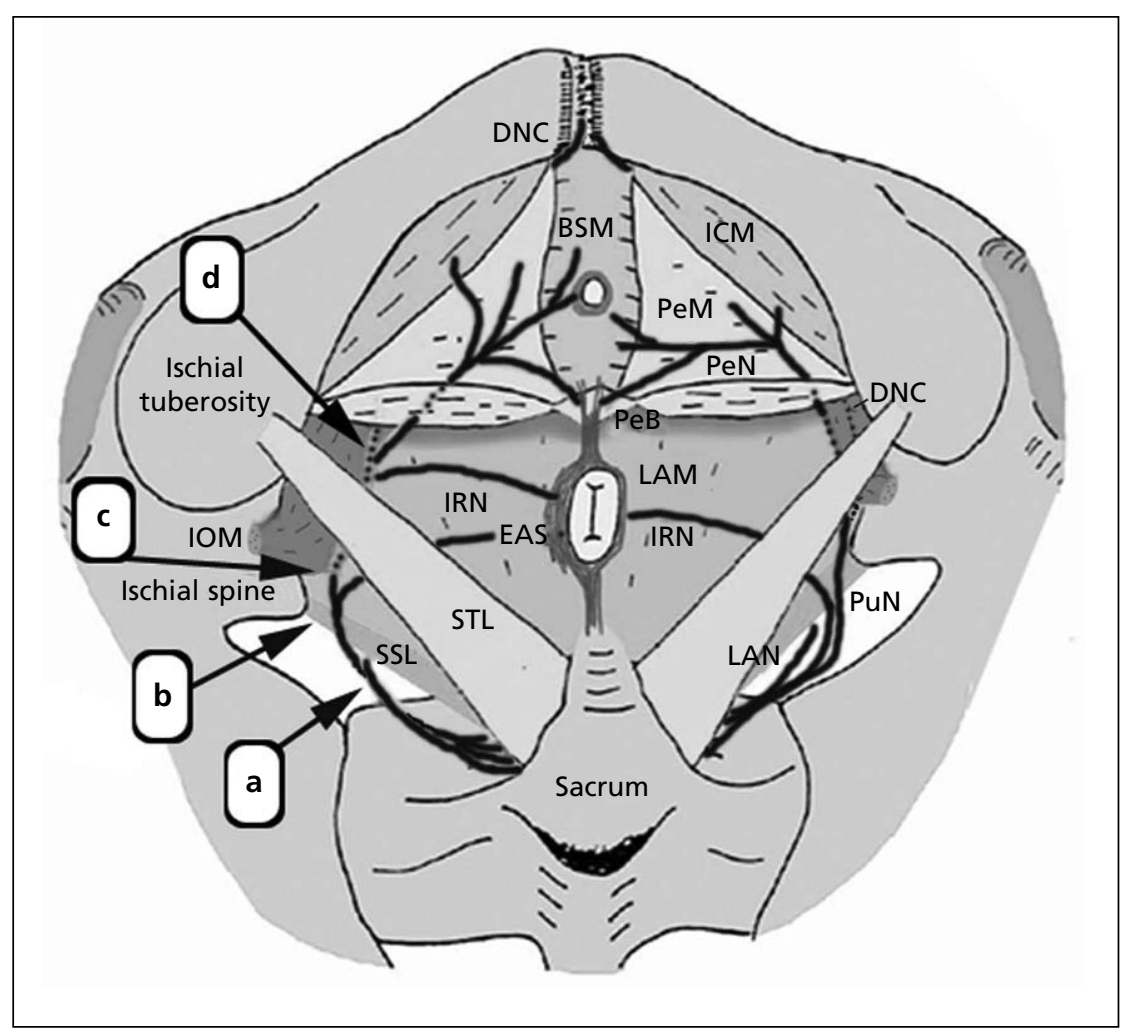


ineal nerves have a more inferior and convex trajectory; thus corresponding more closely to the canal description of Alcock (Figures $\mathbf{1}$ and 2d). Yet, the nerve trajectories are difficult to trace by modern imaging techniques such as computer tomography (CT) and magnetic resonance imaging (MRI) and it becomes important to trace such variations by the traditional way, i.e. by anatomical dissection of cadavers after CT and MRI, eventually to establish an algorythm identification in modern scanning methods. To cure urinary incontinence the separate tra-
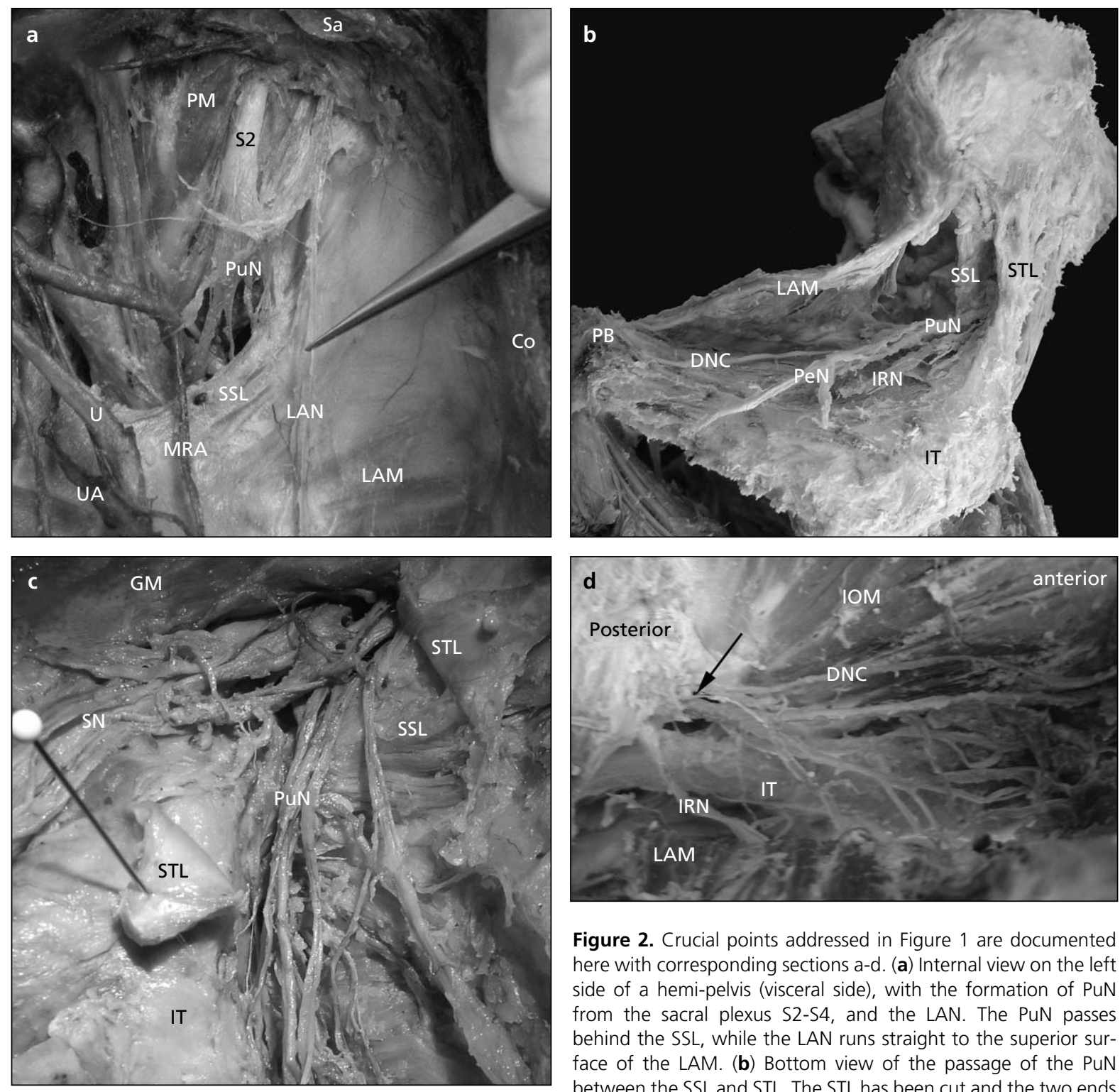

Figure 2. Crucial points addressed in Figure 1 are documented here with corresponding sections a-d. (a) Internal view on the left side of a hemi-pelvis (visceral side), with the formation of PuN from the sacral plexus S2-S4, and the LAN. The PuN passes behind the SSL, while the LAN runs straight to the superior surface of the LAM. (b) Bottom view of the passage of the PuN between the SSL and STL. The STL has been cut and the two ends were fixed with pins to show the trajectory of nerves that enter the perineum. In this case the PuN has already divided into different branches including the inferior rectal nerve, with a trajectory into the ischio-anal fossa. (c) Inferior view of a right side of plastinated hemi-pelvis, showing the PuN and IRN leaving the ligament clamp (formed by STL and SSL). The pudendal canal has been dissected to show the individual nerves. The PuN gives off several perineal nerves that are included in the canal. The branch that innervates the levator ani muscle is passing directly towards the EAS muscle. (d) The DNC is branching off at spine (arrow) and becomes the most superior nerve that runs straight to the pubis along the IOM. This arrangement is seen in two thirds of cases. CB: coxal bone; Co: coccyx; DNC: dorsal nerve of the clitoris; EAS: external anal sphincter; GM: gluteus maximus; IOM: internal obturator muscle; IRN: inferior rectal nerve; IT: ischial tuberosity; L5: fifth lumbar vertebra; LAM: levator ani muscle; LAN: levator ani nerve; MRA: middle rectal artery; OA+V: obturator artery and vein; ON: obturator nerve; PB: pubic bone; PeN: perineal nerve; PM: piriformis muscle; PuN: pudendal nerve; S2: second sacral ramus; Sa: sacrum; STL: sacrotuberous ligament; TA: tendinous arch; U: urethra; UA: uterine artery. 
jectory of the DNC may be of importance, i.e. when slings are fixed in the obturator membrane or with procedures that pass through the obturator foramen. ${ }^{[1,17]}$ Possibly leading to a loss of clitoridial sensitivity when the nerve is damaged.

\section{Conclusion}

Here, we demonstrated that it is essential to pay a particular attention to nerve trajectories in relation to surgery and postoperative pain. We also underline that some nerve variations need to be presented in undergraduate medical teaching to raise an awareness of the importance of anatomical topography.

An evaluation of this form of teaching showed that more than $80 \%$ of students were satisfied, but they felt that too much is presented and that the time is not sufficient to assimilate. Although students know the different structures in theory, when it comes to indicate the structures on prosected specimens, many students are less sure. An other and pertinent comment, is the lack of time. Two hours for self-directed learning is by far sufficient to consolidate the knowledge. This has become evident when students had to identify structures on CT and MRI scans. Students were very interested, but they lacked the three-dimensional view of the levator ani muscle. Most textbooks present the LAM in a gynecological view, therefore it may appear as plane and flat structure. Yet, it is a funnel-like structure, arranged around various organs and stabilizing the structural organization like a cable bridge. ${ }^{[36]}$ More time is needed to be spent with plastinated slices of the perineum to understand the anatomical topography of the pelvic floor in form of self-directed learning.

\section{Acknowledgments}

The authors thank Gaël Kuhn, Jonathan Laureçon and Nathalie Hoffer for their help in pelvic dissections, and the DBCM for its unrestricted support.

\section{References}

1. Williams PL, Bannister LH, Berry MM, et al. Gray's Anatomy. 38th ed. Churchill Livingston: New York; 1995.

2. Rosse C, Gaddum-Rosse P. Hollinshead's Textbook of Anatomy. 5th ed. New York: Lippincott-Raven Publishers; 1997.

3. Moore KL, Dalley AF. Clinically Oriented Anatomy. Baltimore: Lippincott Williams \& Wilkins; 1999.

4. Juenemann K-P, Lue TF, Schmidt RA, Tanagho EA. Clinical significance of sacral and pudendal nerve anatomy. J Urol 1988;139:74-80.

5. Vodusek DB. Anatomy and neurocontrol of the pelvic floor. Digestion 2004;69:87-92.
6. Barber MD. Contemporary views on female pelvic anatomy. Cleve Clin J Med 2005;72 Suppl 4:S3-11.

7. Wallner C, Maas CP, Dabhoiwala NF, Lamers WH, DeRuiter MC. Innervation of the pelvic floor muscles: a reappraisal for the levator ani nerve. Obstet Gynecol 2006;108(3 Pt 1):529-34.

8. Grigorescu BA, Lazarou G, Olson TR, et al. Innervation of the levator ani muscles: description of the nerve branches to the pubococcygeus, iliococcygeus, and puborectalis muscles. Int Urogynecol J 2007;19:107-16.

9. Tamakawa M, Murakami G, Takahashi M, Kato T, Hareyama M. Fascial structures and autonomic nerves in the female pelvis. A study using macroscopic slices and their corresponding histology. Anat Sci Int 2003;78:228-42.

10. Otcenasek M, Baca V, Krofta L, Feyereisl J. Endopelvic fascia in women: shape and relation to parietal pelvic structures. Obstet Gynecol 2008;111:622-30.

11. Spinosa J-P, Riederer BM. De l'importance de l'anatomie. L'agenda Gynecologie 2007;49:6-8.

12. DeLancey JO. Anatomy and physiology of urinary continence. Clin Obstet Gynecol 1990;33:298-307.

13. Shafik A. Neuronal innervation of urethral and anal sphincters: surgical anatomy and clinical implications. Curr Opin Obstet Gynecol 2000;12:387-98.

14. McGuire EJ, Fitzpatrick CC, Wan J, et al. Clinical assessment of urethral sphincter function. J Urol 1993;150:1452-54.

15. Fritsch H, Lienemann A, Brenner E, Ludwikowski B. Clinical anatomy of the pelvic floor. Adv Anat Embryol Cell Biol 2004;175:III-IX, 1-64.

16. Whiteside JL, Walters MD. Anatomy of the obturator region: relations to a trans-obturator sling. Int Urogynecol J Pelvic Floor Dysfunct 2004;15:223-6.

17. Spinosa J-P, Dubuis PY, Riederer BM. Transobturator surgery for female stress incontinence: a comparative anatomical study outside-in vs inside-out techniques. BJU Int 2007;100:1097-102.

18. Shafik A. A new concept of the anatomy of the anal sphincter mechanism and the physiology of defecation. Invest Urol $1975 ; 13: 175-82$

19. Shafik A, Ahmed I, Shafik AA, El-Ghamrawy TA, El-Sibai O. Surgical anatomy of the perineal muscles and their role in perineal disorders. Anat Sci Int 2005;80:167-71.

20. Labat JJ, Robert R, Bensignor M, Buzelin JM. Neuralgia of the pudendal nerve. Anatomo-clinical considerations and therapeutical approach. [Article in French] J Urol (Paris) 1990;96:239-44.

21. Amarenco G, Kerdraon J, Bouju P, et al. Treatments of perineal neuralgia caused by involvement of the pudendal nerve [Article in French]. Rev Neurol (Paris) 1997;153:331-4.

22. Bautrant E, de Bisschop E, Vaini-Elies V, et al. Modern algorithm for treating pudendal neuralgia: 212 cases and 104 decompressions. [Article in French] J Gynecol Obstet Biol Reprod (Paris) 2003;32(8 Pt 1):705-12.

23. Beco J, Climov D, Bex M. Pudendal nerve decompression in perineology: a case series. BMC Surg 2004;4:15.

24. Ricciardi R, Mellgren AF, Madoff RD, Baxter NN, Karulf RE, Parker SC. The utility of pudendal nerve terminal motor latencies in idiopathic incontinence. Dis Colon Rectum 2006;49(6):852-7.

25. Berkley KJ, Rapkin AJ, Papka RE. The pains of endometriosis. Science 2009;308:1587-9. 
26. Spinosa J-P, de Bisschop E, Laurençon J, Kuhn G, Riederer BM. Differential staged sacral reflexes allow a localization of pudendal neuralgia. Pelviperineology 2009;28:24-8.

27. von Hagens G. Heidelberg Plastination Folder. Anatomisches Institut I, Universität Heidelberg. 1985/1986; D6900, Heidelberg.

28. Shafik A, Doss SH. Pudendal canal: surgical anatomy and clinical implications. Am Surg 1999;65:176-80.

29. Shafik A, el-Sherif M, Youssef A, El-Sibai O. Surgical anatomy of the pudendal nerve and its clinical implication. Clin Anat 1995;8:110-5.

30. Beco J, Mouchel J. Traitement de la douleur périnéale et de l'incontinence par la décompression chirurgical du derf pudendal. http://www.perineology.com/files/pudendal_nervefr.htm 2005;03/02/2005:1-13.

31. Richter K, Albrich W. Longterm results following fixation of the vagina on the sacrospinous ligament by the vaginal route (vaginofixatio sacrospinalis vaginalis). Am J Obstet Gynecol 1981;141:811-6.
32. Lazarou G, Grigorescu BA, Olson TR, Downie SA, Powers K, Mikhail MS. Anatomic variations of the pelvic floor nerves adjacent to the sacrospinous ligament: a female cadaver study. Int Urogynecol J 2008;19:649-54.

33. Cruikshank SH. Sacrospinous fixation- should be performed at the time of vaginal hysterectomy? Am J Obstet Gynecol 1991;164:1072-6.

34. Karram MM, Walters MD. Surgical treatment of vaginal vault prolapsed enterocele. In: Walters MD, Karram MM, editors. Urogynecology and Reconstructive Pelvic Surgery. Philadelphia: Mosby Elsevier; 2007. p. 262-7.

35. Alcock B. Iliac arteries. In: Todd RB, editor. The Cyclopedia of Anatomy and Physiology. Vol. 2. London: Longman, Brown, Green, Longmans, Roberts; 1839. p. 827-850.

36. Petros PP. The female pelvic floor: function, dysfunction and management according to the integral theory (Chapter 2). The Anatomy and Dynamics of Pelvic Floor Function and Dysfunction. Heidelberg: Springer; 2004. p. 14-47.

Correspondence to: Dr. Beat M. Riederer

Department of Cell Biology and Morphology

University of Lausanne Rue du Bugnon 9

1005 Lausanne, Switzerland

Phone: ++4121692 51 54; Fax: ++4121692 5105

e-mail: beat.riederer@unil.ch

Conflict of interest statement: No conflicts declared. 